\title{
Os Conceitos Geométricos na Obra de Molina e Rico (1970)
}

\section{Geometric Concepts in the Work of Molina and Rico (1970)}

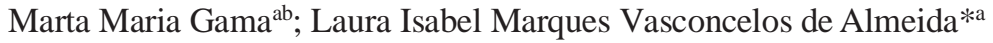 \\ aUniversidade de Cuiabá, Programa de Pós-Graduação Stricto Sensu em Ensino. MT, Brasil. \\ ' Centro Universitário UniCathedral de Barra do Garças. MT, Brasil. \\ *E-mail: lauraisabelvasc@hotmail.com.
}

\begin{abstract}
Resumo
A coletânea "Criança, Geometria, Aritmética" de Molina e Rico, publicada no ano de 1969, foi objeto de estudo da pesquisa de Mestrado em Ensino do Programa de Pós-Graduação da Universidade de Cuiabá (UNIC). O artigo tem como objetivo destacar a análise empreendida nos quatro dos seis livros inventariados no Colégio Liceu Cuiabano, com o intento de compreender como os conteúdos de Geometr ia foram trabalhados na escola primária de Mato Grosso na década de 1970. Ancorada na dimensão metodológica histórico-cultural, a pesquisa se centra nos fundamentos teóricos de autores que discutem com propriedade os conceitos Matemáticos em destaque nos livros didáticos. O estudo revela que a Geometria se constitui como um saber elaborado ao longo do tempo e destaca os primeiros elementos sistema tizados da Geometria em destaque: ponto, reta, plano, polígonos, congruência e ângulos que foram sendo construídos, historicamente, pela cultura escolar e disseminada pela escola primária de Mato Grosso.
\end{abstract}

Palavras-chave: Ensino de Geometria. Cultura Escolar. Livro Didático.

\begin{abstract}
The collection "Child, Geometry, Arithmetic" by Molina and Rico, published in 1969, was the object of study by the Master's in Education research of the Graduate Program at University of Cuiabá (UNIC). The article aims to highlight the analysis undertaken in four of the six books inventoried at Colégio Liceu Cuiabano, with the intention of understanding how the geometry contents were worked in the primary school of Mato Grosso state in the 1970s. Anchored in the historical-cultural methodological dimension, the research focuses on the theoretical foundations of authors who properly discuss the mathematical concepts highlighted in textbooks. The study reveals that geometry is constituted as knowledge elaborated over time and highlights the first systematized elements of geometry highlighted: point, line, plane, polygons, congruence and angles that have been historically constructed by the school culture and disseminated by the primary school of Mato Grosso state.
\end{abstract}

Keywords: Geometry Teaching, School Culture, Textbook.

\section{Introdução}

Neste artigo são analisados os conteúdos de Geometria destacados na coletânea "Criança, Geometria, Aritmética" de Molina e Rico, publicada no ano de 1969, e tudo indica que na década de 1970, os livros foram utilizados na escola e formação de professores primários mato-grossenses. A obra inventariada no Colégio Estadual Liceu Cuiabano foi objeto de estudo da Pesquisa de mestrado, recentemente defendida no Programa de Pós-Graduação da Universidade de Cuiabá, em associação ampla com o Instituto Federal de Educação. Os volumes analisados apontam vestígios significativos da Geometria disseminada na Escola Normal e no Ensino Primário no período delimitado da pesquisa.

Ao se analisar os livros didáticos, Chartier (1991) ressalta sobre a importância de situar o autor na historicidade de sua produção para que possa analisar sua intenção. Na elaboração de uma obra didática, neste caso específico, da coletânea "Criança, Geometria, Aritmética", são criados diferentes sentidos e se torna fundamental reconhecer as estratégias que autores e editores tentavam impor por meio da leitura dirigida. No dizer de Chartier (1991), algumas estratégias utilizadas se tornam explícitas apelando ao discurso e outras subentendidas, "fazendo do texto uma maquinaria (autor, editor, contexto e lugar de produção) que necessariamente deve impor uma justa compreensão (CHARTIER, 1991, p. 123)".

$\mathrm{O}$ artigo tem como objetivo destacar a análise empreendida nos quatro dos seis livros inventariados no Colégio Liceu Cuiabano, com o intento de compreender como os conteúdos de Geometria foram trabalhados na escola primária de Mato Grosso na década de 1970.

Neste cenário é relevante conhecer a obra que, segundo Molina e Rico (1969), possibilita a adaptação do ensino à diversidade dos Programas de ensino e às necessidades específicas de cada classe, descartando os inconvenientes de um ensino organizado segundo um único modelo. A coletânea analisada é rica em detalhes e destaca a sequência didática 
de ensino da época para que o professor tenha sucesso nos exercícios propostos. Ainda, os autores ressaltam a importância de despertar no estudante a autonomia e independência para o estudo com capacidade de autodireção.

Na coletânea, Molina e Rico (1969) afirmam que os exercícios e tarefas se vinculam aos trabalhos desenvolvidos durante as aulas e devem ser executados pelas crianças. $\mathrm{Na}$ concepção das autoras, os exercícios e tarefas são trabalhos distintos. Os exercícios são mais adequados à fixação das noções de Geometria, são de aplicação imediata. As tarefas têm sentido mais amplo do que os exercícios, permitindo a fixação do conhecimento, a ampliação da aprendizagem e a aplicação do aprendido.

A coletânea "Criança, Geometria, Aritmética" se compõe de seis livros didáticos, no entanto, se teve acesso apenas a quatro volumes com possibilidades de análises dos conteúdos que foram sistematicamente organizados em cinco unidades: o ponto, o plano e as figuras planas, polígonos, congruência e ângulos indicando como os professores aprendiam e ensinavam os conteúdos de Geometria na escola primária mato-grossense.

\section{Material e Métodos}

A pesquisa desenvolvida na vertente histórico-cultural se insere nos estudos da História da Educação Matemática, campo que demanda um processo de aprimoramento dentro da História da Educação, em relação ao ensino dessa disciplina. Neste contexto são feitas interlocuções com historiadores e autores entre os quais se destacam Bloch (1990), Chartier (1990), Medeiros (2003) e Valente (1999) que contribuem para melhor compreensão da historicidade das fontes de pesquisa e disciplinas escolares.

Medeiros (2003, p. 6) afirma que: "os documentos escolares têm também valor histórico-cultural". Os historiadores contemporâneos consideram os documentos constituídos nas escolas (registros escolares em geral, livro didático, planos de ensino, cadernos escolares, entre outros) como fontes importantes para a História da Educação. Por meio desses acervos, os historiadores podem analisar e reconstituir o cenário educacional e práticas escolares de outros tempos.

Bloch (2001), nos seus estudos, também afirma que "toda investigação histórica supõe desde os seus primeiros passos, que a investigação já tenha uma direção" (2001, p. 27). Neste cenário, a produção histórica aqui realizada se apoia nos livros didáticos inventariados em uma escola pública de Cuiabá/MT, que circulou na década de 1970 e tudo indica que a coletânea foi utilizada para disseminar os conceitos Geométricos na escola primária, concomitante a formação de professores primários.

Chartier (1990) destaca que a escola é um espaço de criação, no qual as disciplinas são produzidas nas relações disseminadas pela cultura escolar. Afirma o autor que o espaço escolar possui uma função criativa e para além dos conteúdos estabelecidos, compõe a prática educativa mediante a preparação pedagógica que utiliza. Ainda ressalta que o estudo histórico da Matemática exige a consideração dos produtos da cultura escolar de outros tempos, considerando os elementos que foram vistos e elaborados em contextos diferentes.

Partindo dessa premissa, a seguir são destacadas as cinco Unidades de Geometria, retratadas pelas autoras Molina e Rico (1969), consideradas o carro chefe dos quatro volumes analisados: o ponto, a reta, o plano, os polígonos, a congruência e ângulos que, posteriormente, são analisadas.

\section{Resultados e Discussão}

\subsection{O Ponto - $1^{\mathrm{a}}$ Unidade}

$\mathrm{Na} 1^{\mathrm{a}}$ unidade da coletânea são interpelados pelas autoras os seguintes conteúdos Geométricos: ponto, reta e semirreta. $\mathrm{O}$ assunto sobre o ponto é apresentado conceitualmente e as noções iniciais são apenas teóricas. As figuras do ponto foram empregadas pelas autoras para iniciar algumas considerações primitivas sobre retas.

Os objetivos de conhecimento da obra determinam que o aluno deveria formar o conceito de ponto, de linha reta, de semirreta e de segmento reto; reconhecer intuitivamente a melhor representação do ponto e linha; perceber figuras geométricas como um conjunto de pontos (MOLINA; RICO, 1969, p. 2). Sobre o conteúdo "O Ponto", no item "Conteúdo a ser ensinado" há uma relação com dezessete conceitos dos quais elencamos três: o ponto geométrico é a figura mais simples; o ponto não possui dimensão, mas ocupa uma posição. Pode-se localizar a posição de um ponto, como apresenta a Figura 1 da $1^{\mathrm{a}}$ unidade.

\section{Figura 1 - O Ponto - $1^{\mathrm{a}}$ Unidade \\ 1: unidade}

\section{O PONTO}
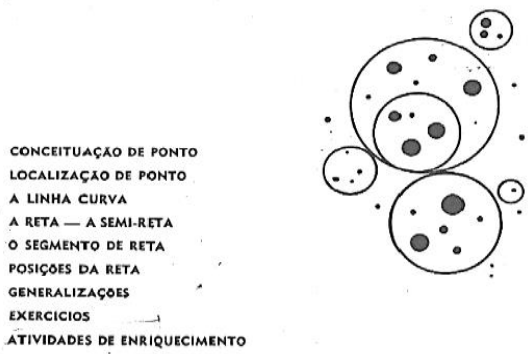

Fonte: Molina e Rico (1969).

Ao se analisar o conteúdo proposto se recorre a Pestalozzi (1946) para tentar compreender a forma de trabalho com a criança. $\mathrm{O}$ autor afirma que o desenvolvimento infantil é a parte fundamental no processo de ensinar: "havia uma ordem natural na evolução do desenvolvimento moral, físico e intelectual, que deveriam ser desenvolvidas mediante 
exercício apropriado" (SOUZA, 2009, p. 4).

Assim, as primeiras experiências de aprendizagem não deveriam ser por meio de gravuras, mas pelo contato direto com objetos. As gravuras teriam uma função auxiliar para a criança, em seguida, iriam para o desenho e assim por diante. Pela percepção, as crianças entrariam em "contato direto com os objetos, depois o conteúdo do objeto observado se expressaria em palavras, permitindo a atividade mental", pois para Pestalozzi (1946) a experiência sensorial era um processo ativo que comprometia, discriminava, analisava e abstraia as qualidades dos objetos (ZANATTA, 2012, p. 107).

Embora as autoras orientem os professores a utilizarem o ensino intuitivo, as crianças não tinham acesso à observação de fatos e objetos. Neste caso é contraditório afirmar que a maneira como os conteúdos eram trabalhados (conceitos e imagens) não se encaixam no princípio do método intuitivo, estava fundamentado na observação de fatos e objetos pelas crianças. No entanto, não se tratava apenas de observar, era preciso criar situações de aprendizagem para que o conhecimento emergisse no entendimento da criança (PINHEIRO, 2012, p. 3). A autora menciona que por meio desse método, o ensino deveria "partir do concreto para o abstrato valorizando a aquisição do conhecimento pelos sentidos com a ênfase que este fosse o mais concreto possível" (PINHEIRO, 2012, p.12).

Em relação à reta, o procedimento é o mesmo, com dezessete tópicos dos quais se destacam três: "Uma reta pode se apresentar em três posições: horizontal, vertical e inclinada; a reta é horizontal quando segue a direção da água em repouso; duas retas podem estar contidas em um mesmo plano ou em planos diferentes (MOLINA; RICO, 1969).

Na mesma página existem o que as autoras denominam de elementos a respeito de conceitos Geométricos, entre essas há um relato sobre a ligação entre a Geometria como parte inerente à Matemática, que estuda as propriedades das figuras e as relações que estas guardam entre si; a Geometria parte das noções não definidas, que são conceitos primitivos; das noções não demonstráveis, que são os axiomas ou postulados. Axiomas são proposições aceitas sem demonstrações para a melhor compreensão e aprendizado da Matemática e da Geometria. São conhecidos como postulados e proposições aceitas sem demonstrações. Um axioma importante e muito útil na Geometria envolve o estudo do ponto, da reta e do plano. Na obra de Euclides, segundo Roque (2012), se observa que o autor não se restringiu apenas a área da Geometria plana de figuras retilíneas, da construção e propriedades de triângulos, paralelismo, equivalência de áreas e teorema "de Pitágoras" (ROQUE, 2012, p.163-164).

Commandino (1944, p.4) também destaca que a obra "Os Elementos" apresenta vinte e três definições de ponto, linha, reta, círculo e nas suas sete primeiras definições, destacam-se os conceitos de ponto, reta e plano.

Pelo nível de ensino ofertado, as autoras partem de um menor grau de dificuldade, porém não se consegue descobrir para que série essa unidade foi destinada. Ao ensinar sobre reta, o que se percebe é a valoração do ponto. De acordo com a Figura 2, a reta é considerada pelas autoras, a mais simples das linhas. Apresentam figuras que indicam que por um ponto dado passam infinitas retas. Por dois pontos distintos passa uma única reta. A reta é ilimitada, mas um ponto qualquer pode dividi-la em duas porções denominadas semirretas.

Figura 2 - Reta - $1^{\text {a }}$ Unidade

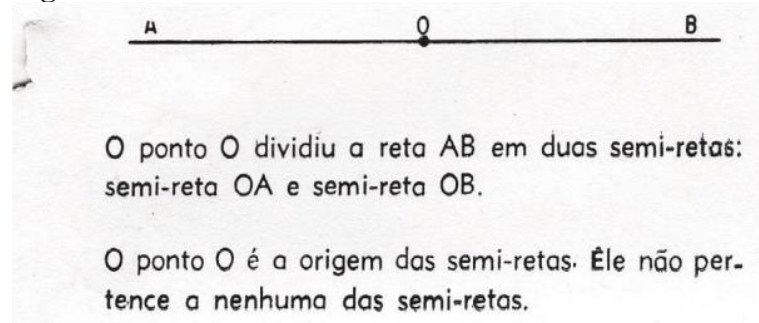

Fonte: Molina e Rico (1969).

Na obra é reiterado que os objetivos propostos se preocupam com os conhecimentos e o comportamento, já que visam dotar a criança de certo número de conhecimentos e técnicas, desenvolver habilidades à medida que se processa a aquisição dos conhecimentos como consequência dessa própria aquisição.

A necessidade de atender a essa dualidade de objetivos (conhecimento e comportamento) decorre da atitude diante da matéria e, principalmente, de como se processa esse ensino. Em cada unidade de ensino há uma relação dos objetivos concernentes ao conhecimento, porém em relação aos objetivos comportamentais, o mesmo não acontece, uma vez que, explicitamente, existe a possibilidade de um mesmo assunto oportunizar o desenvolvimento de vários comportamentos simultaneamente, e ninguém melhor que o professor para precisar as disposições mais convenientes a serem formadas em seus alunos (MOLINA; RICO, 1969).

Observa-se que a técnica de discussão é, frequentemente, sugerida nas atividades para formação de conceitos, a qual demonstra a possibilidade de ser ativada em classe, no sentido de encaminhamento da criança para as descobertas e consequentes generalizações. As autoras, na explicação inicial, argumentam que as sugestões de como orientar a discussão não são caminhos rígidos e únicos, são direções que, necessariamente, terão de sofrer modificações de sorte a dar atendimento às necessidades sentidas pela criança e pela escola. Os exercícios de forma alguma substituem as situações de experiências que o professor deve proporcionar à criança, para formação dos conceitos. Servirão para sistematizar, fixar, verificar os conhecimentos adquiridos.

No entanto, quando se analisam as lições se percebe que as explicações ficam no nível da observação, enquanto o professor expõe e conduz a criança ao reconhecimento intuitivo do ponto e da linha, desde os primeiros estágios. Apresentam modelos de retas perpendiculares, oblíquas, ângulos, curva. Para Molina e Rico (1969, p.5): "a conceituação de curva e 
de reta e suas posições vai depender da compreensão que a criança tem de direção e sentido". Esclarece sobre as direções (horizontal, vertical e inclinada) e traz demonstrações de acordo com a Figura 3.

Figura 3 - Retas Perpendiculares $-1^{\text {a }}$ Unidade

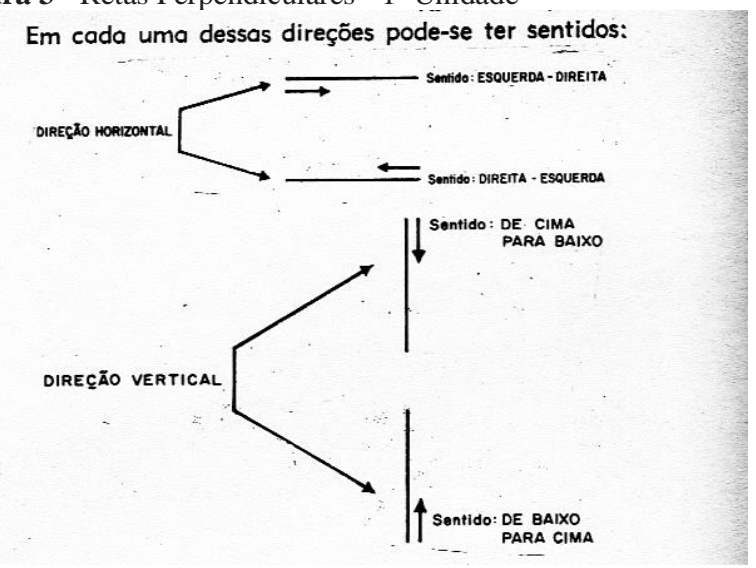

Fonte: Molina e Rico (1969).

Nas páginas posteriores começam as sugestões de atividades, com exercícios de fixação que são reforçados os conhecimentos sobre Pontos, Retas e Semirretas, conforme aponta a Figura 4. Entende-se que até meados de 1960, as obras lançadas no Brasil apresentavam os conteúdos por meio de conceitos, de teoremas e de corolários, em um modelo próximo da geometria euclidiana, acompanhados de numerosos exercícios que requeriam a comprovação do aluno.

Figura 4 - Modelos gráficos do Ponto - $1^{\text {a }}$ Unidade RECONHECENDO MODELOS GRAFICOS DO PONTO

Fazer, na lousa, várias representações do ponto e explicar à criança que essas representações são modelos de ponto.

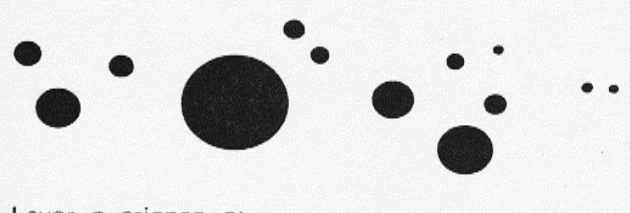

Levar a criança a:

- desenhar alguns modelos de ponto;

- colorir um conjunto de pontos:

- mostrar modelos de ponto:

- na sala de aula (pequenas manchas nas paredes, móveis, teto, chão, lousa, etc.);

- em pedaços de papel e de tecidos:

- em gravuras;

- em fôlhas de plantas, flôres;

- em brinquedos.

Fazer numa fôlha de papel, à vista da criança, vários furos (com agulhas, alfinêtes e pregos de diferentes grossuros). Levantar o problema:

Fonte: Molina e Rico (1969).

No contexto das atividades propostas no livro, há uma orientação aos professores para que registrem na lousa uma sequência de quatro desenhos com pontos enfileirados. Depois de solicitar às crianças que expliquem os desenhos. Até aqui, a Geometria ensinada nos livros adota uma abordagem intuitiva, porque acentua as noções de figura geométrica, conjuntos de pontos do plano que se concretiza na análise da obra em geral.

A página 15 destaca uma síntese do que foi estudado, denominado pelas autoras de Generalizações: o ponto e a linha são figuras geométricas; pode-se representar o ponto e a linha com modelos; um ponto em uma reta pode dar origem a uma semirreta; dois pontos podem dar origem a um segmento de reta; um ponto pode dar origem a muitas semirretas. A seguir levantam questionamentos para que a criança responda, evidenciado na Figura 5.

Figura 5 - Retas Paralelas - $1^{\text {a }}$ Unidade

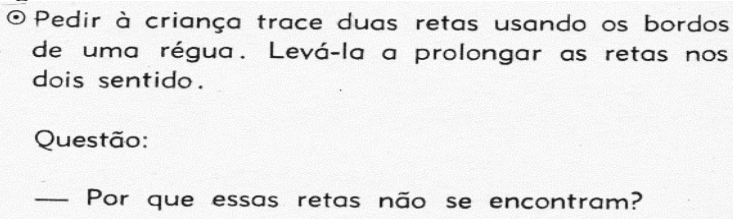

Levar a criança a medir a distância entre as duas retas em vários pontos para encontrar a resposta.

Apresentar vários pares de retas paralelas. Pedir à criança meça a distância entre uma reta e outra em vários pontos. Discutir os resultados obtidos.

Apresentar exemplos e contra-exemplos de retas paralelas. Levar a criança a prolongar as retas, medir a distância que guardam entre si e numerar as que estão sempre a igual distância.

Fonte: Molina e Rico (1969).

$\mathrm{Na}$ primeira unidade, os exercícios estão direcionados para retas perpendiculares, coincidentes e concorrentes, paralelas e reversas. Finalizando, as autoras disponibilizam mais atividades de enriquecimento como a construção de um fio de prumo; construção de um nível; leitura informativa, dando como exemplo o trabalho do marceneiro que utiliza o fio de prumo e o nível como ferramentas do seu trabalho.

\subsection{O Plano e as Figuras Planas - $2^{\mathrm{a}}$ Unidade}

$\mathrm{Na} 2^{\mathrm{a}}$ unidade da obra são abordados os tópicos: plano e as figuras planas. Observa-se que os conceitos, figuras geométricas, atividades de aprendizagem e fixação foram novamente utilizados pelas autoras para ensinar Geometria para as crianças. De acordo com a Figura 6, constata-se previamente os conteúdos a serem trabalhados.

Em relação às atividades propostas, Dienes e Goldin (1977, p.1) destacam que:

A geometria é a exploração do espaço. Uma criança, desde seu nascimento, explora o espaço. Primeiramente o olha, depois o sonda com seus braços e pernas visando a descoberta, e enfim se desloca nele. É preciso um tempo bastante longo para desenvolver as ideias de perspectiva, de distância, de profundidade; noções como as de dentro e fora, diante e atrás, antes e depois, e assim por diante. As primeiras noções de geometria não têm nada a ver com a medida. Uma criança preocupa-se muito pouco com a distância exata dos objetos, de seus movimentos ou do ângulo sob o qual as coisas são vistas). 
Figura 6 - Plano e Figuras Planas - $2^{\text {a }}$ Unidade

\section{2: unidade O PLANO E AS FIGURAS PLANAS}

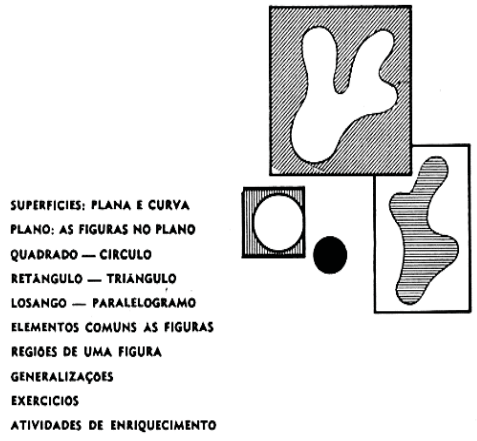

Fonte: Molina e Rico (1969).

À medida que os conteúdos do livro foram analisados se percebia que o sistema escolar brasileiro confirmava a dualidade da escola entre a classe operária e a elite. No dizer de Miguel e Miorim (2004), as noções próprias da Geometria, bem como as constituições geométricas e realce ao método dedutivo e prático faziam parte do rol dos conteúdos que os alunos provenientes das elites acessavam, embora os livros de Matemática não trouxessem esses conteúdos (ZUIN, 2002). Segundo os autores, apesar da Geometria ter sido fustigada do currículo, seus conteúdos continuaram nas escolas das elites brasileiras.

Pavanello (1989), em suas análises, destaca que em relação ao estudo de Geometria, o povo não tem acesso a essa, exceto se tiver utilidade prática: "no que se refere às profissões, e até isso mesmo lhe é negado, à medida que ampliam as oportunidades educacionais das classes inferiores da sociedade, reduzindo o caráter diretamente profissional da educação" (PAVANELLO, 1989, p.100).

Os objetivos de conhecimento apresentados para o professor na $2^{\mathrm{a}}$ unidade são destacados pelas autoras: formar o conceito de superfície plana e de superfície curva; formar conceito de plano; diferenciar figuras de contorno arredondado de figuras por segmentos de retas; interpretar os elementos de uma figura formada por segmento de reta; reconhecer região interna e externa de uma figura e caracterizá-la. Os conteúdos a serem ensinados são: Quadrado; Círculo (disco); Retângulo; Triângulo; Losango e Paralelogramo. As autoras dão informações que são complementadas com figuras. Não há indício de que as crianças façam, mas apenas observam. $\mathrm{Na}$ Figura 7, a obra apresenta as várias posições de uma reta (geratriz) para se obter uma diretriz. Não há explicações sobre os termos geratriz e diretriz. São evocados como se surgissem do nada.
Figura 7 - Geratriz - $2^{\mathrm{a}}$ Unidade
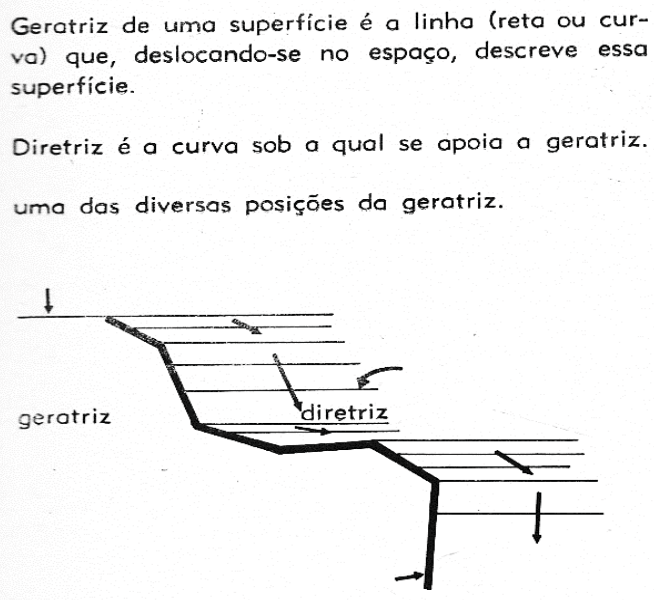

Fonte: Molina e Rico (1969).

Em seguida, apresentam a Geometria espacial e evidenciam que ao conceber um plano se deve imaginar porções do Espaço. Explicam que se em um plano existem infinitos pontos, também existem infinitas retas. Uma reta pode dividir o plano em duas partes distintas entre si e se denomina Semi-plano, portanto, a reta é a origem dos Semiplanos. Observa-se que as autoras utilizam duas formas de escrever o termo Semiplano. Ora escrevem Semi-plano, ora escrevem Semiplano. Conceituam e distinguem figuras planas e espaciais ou não-planas.

Demonstram, por meio da Figura 8, as regiões internas e externas de um Plano. Essas fontes, as quais se está consultando são fundamentais para averiguar a presença da Geometria nos cursos de formação de professores primários e como eram ensinados aos alunos.

Figura 8 - Plano em duas regiões - $2^{\mathrm{a}}$ Unidade

Uma figura, desenhada em um plano, divide êsse plano em duas regiões:

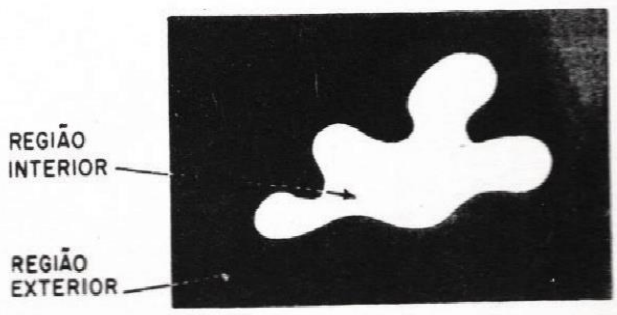

Fonte: Molina e Rico (1969).

Ao ensinar sobre a figura assentada em uma base, mencionam que a criança tem noção intuitiva de espaço. Para ensinar noção de superfície plana e curva, apresentam um suporte, em cada figura, que sustém uma barra (diretriz). Para as autoras, a representação física traz dupla vantagem ao ensino, pois permite a formação de conceitos e a percepção da figura plana como elemento componente de outras figuras, como por exemplo, os sólidos. 
Acerca do Espaço, as autoras afirmam ser algo que abrange tudo, ou seja, algo que parece não ter tamanho. É também um lugar maior ou menor, assim, como o plano, o espaço é uma sobreposição de retas no significado vertical. No dizer de Molina e Rico (1969), na inserção de figuras como o quadrado, o círculo, o retângulo, o triângulo, os alunos as conhecem mesmo que seus conceitos sejam malformados. E complementam afirmando que as crianças precisam apenas dos conceitos, embora tenham dificuldade para interpretar alguns elementos da figura, o que não é novo, já que as aulas sempre ocorrem por meio de explicação do professor e da imagem circunscrita, apontada na Figura 9.

Figura 9 - Figuras geométricas - $2^{\text {a }}$ Unidade
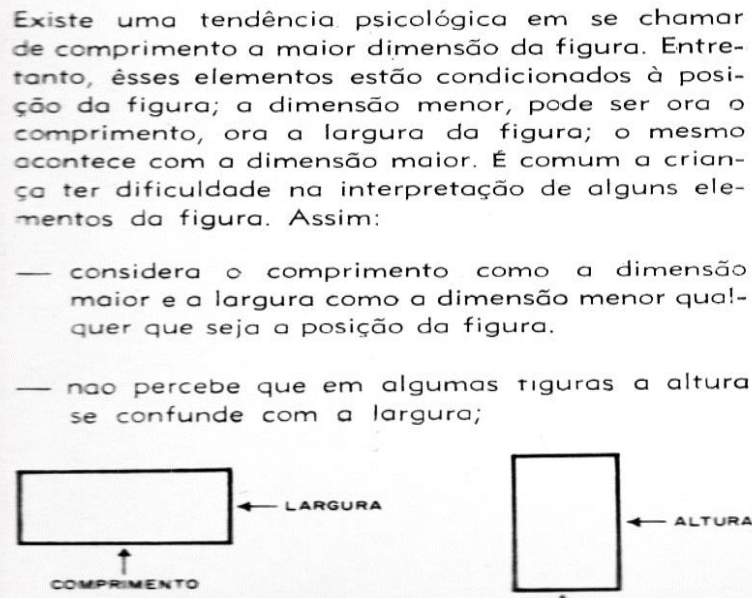

Fonte: Molina e Rico (1969).

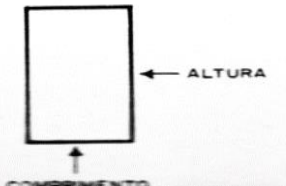

A concepção das autoras é que as crianças não percebem que em algumas figuras só se consideram base e altura, como também não compreendem que qualquer lado pode ser a base da figura, não reconhecem a altura do triângulo de acordo como destaca a Figura 10.

Figura 10 - Figuras geométricas - $2^{\mathrm{a}}$ Unidade - nõo reconhece a altura do triàngulo.
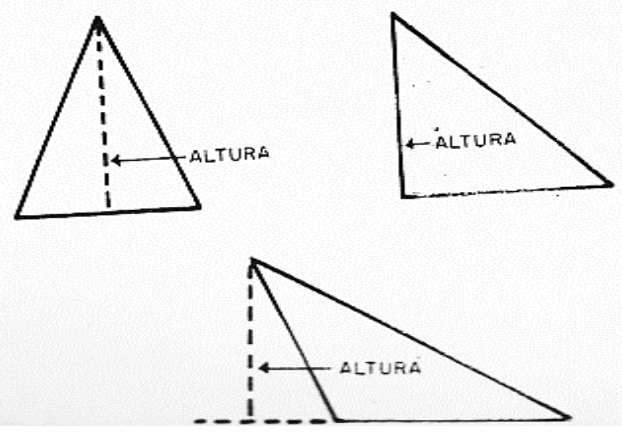

Fonte: Molina e Rico (1969).

As páginas 34 a 50 são dedicadas à sugestão de Atividades de Enriquecimento, exercícios de aprendizagem e de fixação. Também constam tarefas contendo asserções de certo ou errado, atividades de colorir diversas figuras Geométricas, completar orações, entre outras, conforme destacam a Figura 11. As autoras sugerem também que as crianças leiam para que obtenham informações.

Figura 11 - Atividades de Enriquecimento - 2a Unidade atividades de ENRIQQUECIMENTO

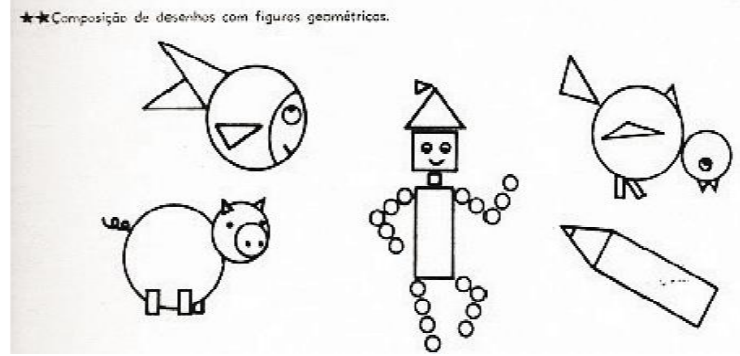

Fonte: Molina e Rico (1969).

Finalizam a unidade sugerindo uma atividade em que as crianças participem da elaboração de um quadro mural intitulado: "Figuras que jáconhecemos"destacado na Figura 12.

Figura 12 - Figuras que já conhecemos - $2^{\mathrm{a}}$ Unidade

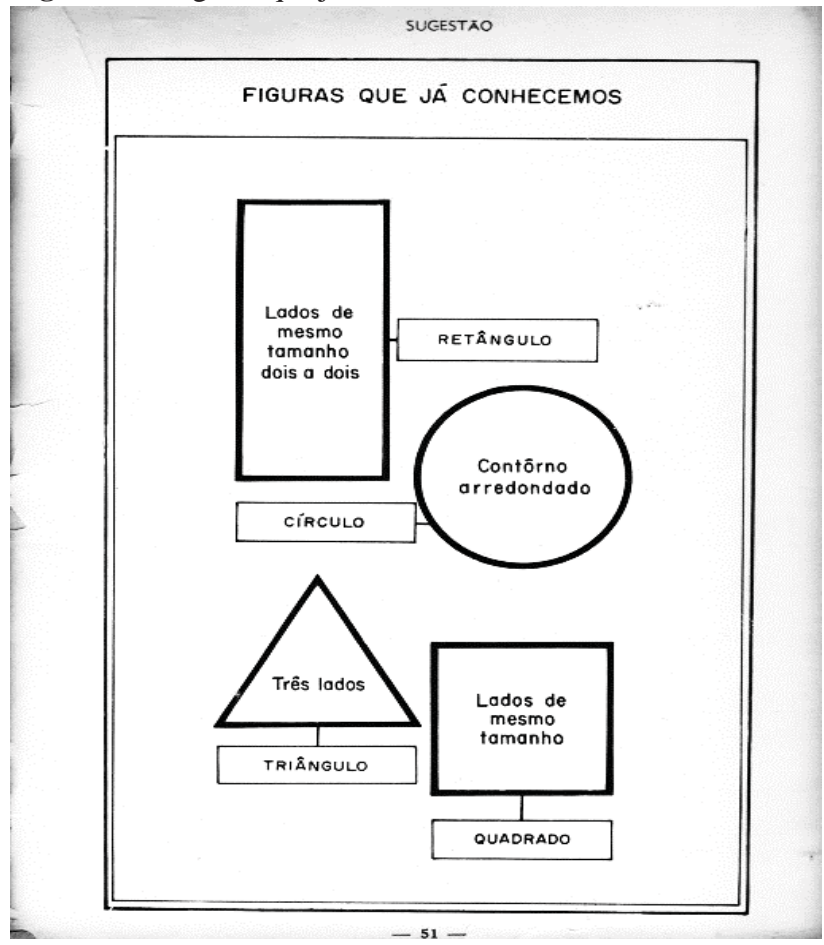

Fonte: Molina e Rico (1969).

\subsection{Polígonos - $3^{\text {a }}$ Unidade}

A $3^{\mathrm{a}}$ unidade do Volume I contempla os objetivos a serem alcançados, tais como: identificar as diferentes espécies de curva; distinguir entre as curvas fechadas simples, as que são polígonos e classificar os polígonos quanto ao número de lados. Quanto aos conteúdos a serem ensinados, são as curvas nos diferentes modos; linha poligonal; triláteros e quadriláteros (Figura 13).

No período em que a coletânea circulou no Estado de Mato Grosso, principalmente, nas décadas de 1960 e 1970, o Movimento da Matemática Moderna (MMM) estava submetido a muitas críticas, mesmo assim essas sugerem em seus livros as práticas adotadas pelo MMM no ensino primário. Nesse primeiro volume há inúmeras informações 
que, segundo as autoras, são importantes para ensinar os conteúdos sugeridos.

Para Molina e Rico (1969), no MMM há uma preocupação com o desenvolvimento de atividades que vão se tornando gradativamente mais elaboradas, até atingir certo grau de abstração, que ocorre no momento do registro presente nos próprios livros do aluno, na tentativa de tornar os conteúdos mais significativos.

Figura 13 - Polígonos - $3^{\mathrm{a}}$ Unidade

\section{3: unidade}

\section{POLIGONOS}
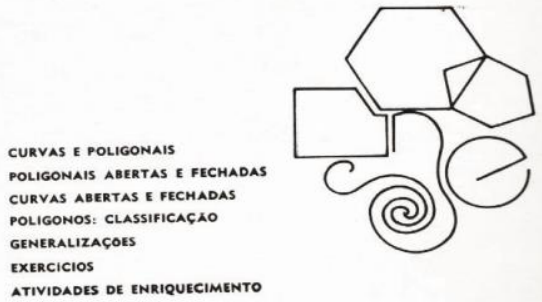

Fonte: Molina e Rico (1969).

A $3^{\mathrm{a}}$ unidade tem como objetivo identificar as diferentes espécies de curva; distinguir entre as curvas fechadas simples e as que são polígonos; classificar polígonos quanto ao número de lados. Os conteúdos tratam das linhas poligonais abertas ou fechadas; os polígonos e suas classificações a partir do número de lados de acordo com a Figura 14. Tudo indica que os conteúdos são direcionados para as $3^{\mathrm{a}} \mathrm{e} 4^{\mathrm{a}}$ séries.

Figura 14 - Polígonos - $3^{\mathrm{a}}$ Unidade

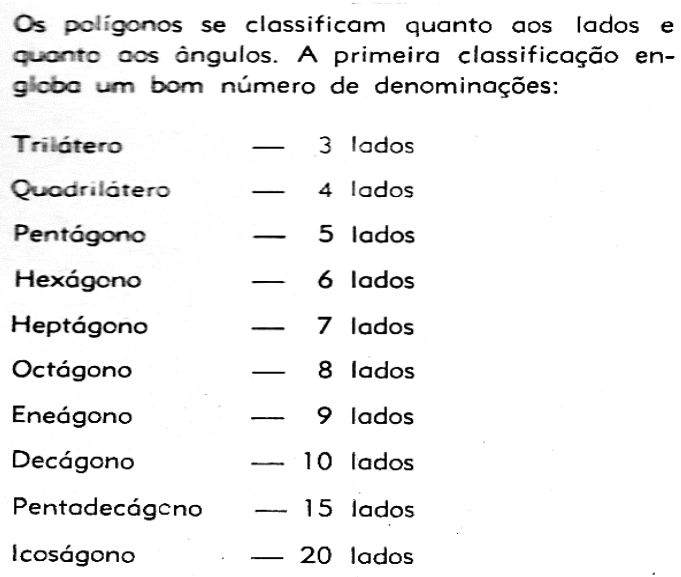

Fonte: Molina e Rico (1969).

Após o estudo dos Polígonos e Linhas poligonais dão continuidade também ao estudo dos trapézios. O círculo e a esfera são trabalhados posteriormente, com atividades que utilizam régua e compasso, embora as crianças observem apenas nos livros, expõem também as relações entre raio e diâmetro e suas definições. Apresentam a ideia de reta secante, tangente. Definem, mais uma vez, o círculo como o conjunto de pontos da circunferência e o conjunto dos pontos internos a essa.

Para falar de esfera, as autoras instruem que não desenhe a esfera, pois o desenho não fará com que a criança entenda suas propriedades, mas o professor deve mostrá-la. Para finalizar, dão o passo a passo para ensinar o comprimento da circunferência, arcos e medidas dos ângulos inscritos a uma circunferência. Por último, sugerem atividades que serão realizadas pelos alunos, na mesma sequência das unidades anteriores. Atividades de desenho, de pintura e completar orações, partindo da observação de figuras geométricas e numerais correspondentes de figuras.

Nas décadas de 1960 a 1980, o MMM foi determinante para as mudanças nos fins tradicionais propostos para a Matemática. Segundo Kline (1976), o objetivo era reformar o currículo tradicional dessa disciplina, pois possuía muitos defeitos e estava voltados apenas para o progresso. Durante a análise do Volume I, as autoras têm um discurso voltado para o MMM, porém o que se observa na obra são apresentações bem superficiais e exercícios repetitivos.

Os que advogavam acerca da Matemática Moderna destacavam que com o raciocínio por trás do método, os alunos passariam a compreender o conceito trabalhado e não precisariam decorar. Gadotti (2008, p. 28) destaca: "no currículo tradicional, basicamente se usa a abordagem lógica, ou seja, começa-se com as definições e provam-se dedutivamente as conclusões".

Antes de iniciar a análise do Volume II, tomou-se como base o referendo acerca dos livros didáticos de acordo com o pensamento de Valente (1999). Para o autor, esse material didático é um produto cultural, sendo necessário entendê-lo como um bem cultural. A despeito disso, esclarece-se que a pesquisadora fez parte de uma geração que se preocupava em adquirir cultura, ou melhor, fazia questão do acesso à cultura.

Desse modo, deve ser tratado como tal para entendêlo em seu processo de produção física, material bem como na conjuntura em que ocorre sua preparação intelectual. Há também que compreender suas múltiplas faces que se cruzam na autoria dos textos, nos modos de circulação que são auferidos aos livros e, sobretudo, na utilização em épocas diferentes.

Partindo desses pressupostos, verifica-se que há um contrassenso nas décadas em que se concentram esta pesquisa (1960 a 1980). Juscelino Kubitschek, ao inaugurar Brasília, em 1960, tinha como lema: "50 anos em 5", ou seja, o desenvolvimentismo se afirmava no Brasil, a partir daquele desafio concretizado. No entanto, isso não foi possível em decorrência do Golpe de 1964 que o Brasil sofreu. A interrupção destes quatro anos elucida esse contrassenso e a escola agrega, em seu currículo, um ensino direcionado para o desenvolvimento econômico do país.

Esse fato contribuiu para o alto índice de evasão, de acordo com o que destaca a Figura 15. No diário de uma professora da $4^{\mathrm{a}}$ série em 1985, no início do ano letivo a turma era composta por 26 alunos, mas somente 5 alunos chegam até o final. 


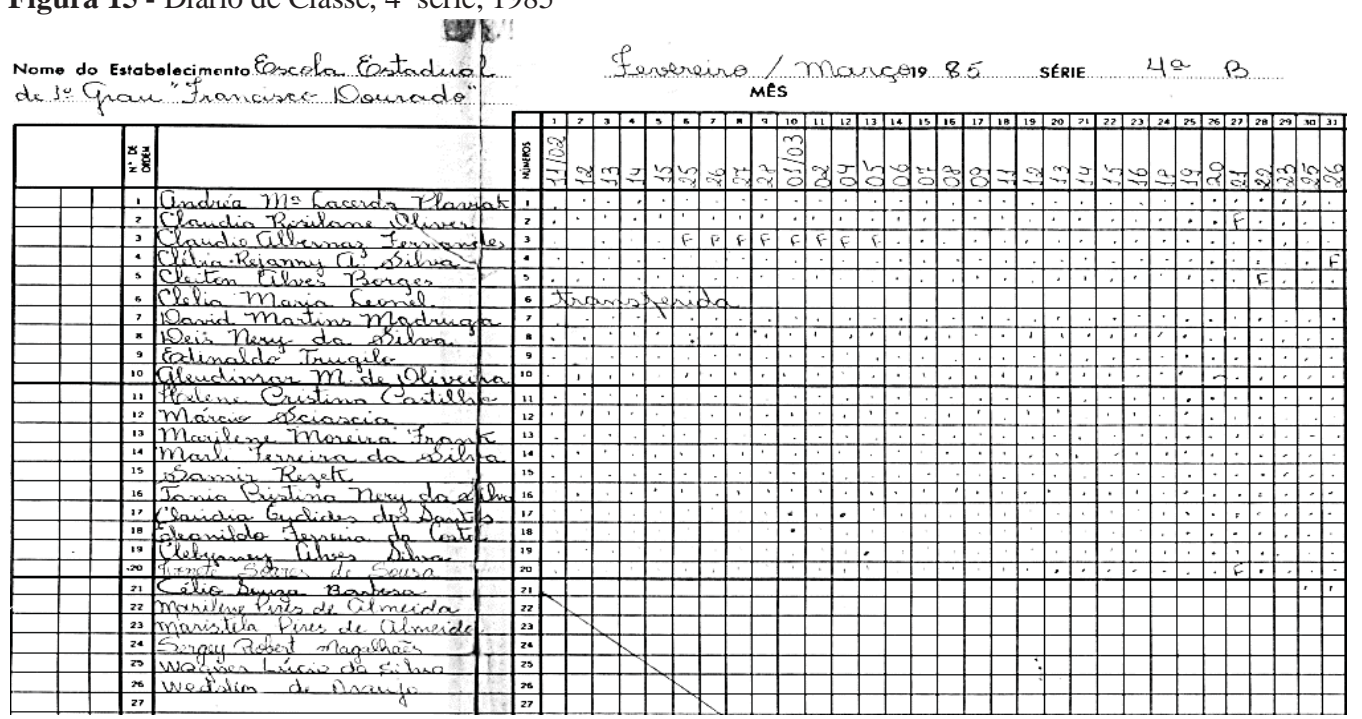

Fonte: Escola Estadual de $1^{\circ}$ grau Francisco Dourado - Barra do Garças/MT.

Os registros chamam a atenção pelo alto índice de alunos que abandonam a escola. Neste contexto, durante o período em que o ensino tradicional vigorava no Brasil e no Mundo, sua base estava assentada na Aritmética, Álgebra, Geometria Euclidiana e Trigonometria, porém com o Movimento da Matemática Moderna, a base curricular da disciplina de Matemática sofre alterações e apresentam na sua estrutura a Teoria dos conjuntos, Topologia e matérias sobre as Congruências.

\subsection{A Congruência - $3^{\mathrm{a}}$ Unidade}

O Volume II da Coletânea de Molina e Rico (1969) destacam sete unidades, iniciando com a $4^{\mathrm{a}}$ indo até a $10^{\mathrm{a}}$, as quais propõem os conteúdos apresentados na Figura 16.

\section{Figura 16 - A Congruência - $4^{\mathrm{a}}$ Unidade \\ 4: unidade \\ A CONGRUENCIA}
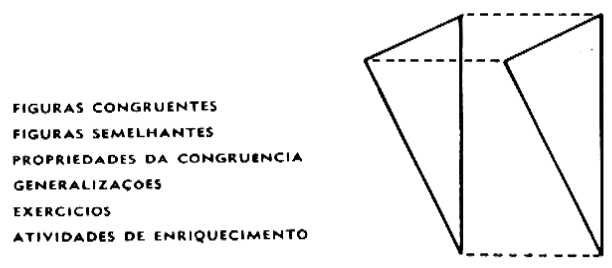

Fonte: Molina e Rico (1969).

Essa coleção foge ao padrão estabelecido nos derradeiros anos em que a Geometria estava inserida na última unidade do livro de Matemática. Nesse caso, só seria ensinada se o professor tivesse tempo para tal. Durante as leituras se percebe que os alunos, ao estudarem Geometria, desenvolvem a capacidade de pensar de modo organizado, compreendendo, delineando e imaginando o Mundo no qual eles estão inseridos.

Os objetivos a serem alcançados nessa unidade são: formar o conceito de congruência e o de semelhança; conhecer os símbolos que exprimem a congruência e a não congruência. Os conteúdos a serem ensinados se relacionam diretamente com as figuras e o símbolo de congruência. As autoras informam que as figuras são definidas como conjuntos de pontos. Para haver coerência com essa teoria, as autoras esclarecem que não se pode dizer que duas figuras são iguais, mesmo que possuam todos os seus elementos iguais. Os triângulos A e $\mathrm{B}$, apesar de possuírem lados e ângulos iguais, não podem ser ditos iguais, porque o triângulo A não é o triângulo $\mathrm{B}$.

Avalia-se que esse conteúdo foi trabalhado na Escola Normal, dado o grau de sua complexidade. O que se percebe também é que o ensino está baseado muito mais na ação de estudar os símbolos e regras do que no significado que eles têm, como está demonstrado na Figura 17.

Figura 17 - Congruência - $4^{a}$ Unidade

- O símbolo de congruência é $\cong$ que se lê congruente com;

- A não congruência é representada pelo símbolo q que se lê não congruente com;

- Duas figuras são semelhantes, quando têm a mesma forma;

- Nas figuras semelhantes, os ângulos que se correspondem são congruentes e os' lados correspondentes são proporcionais.

Fonte: Molina e Rico (1969).

De acordo com Molina e Rico (1969), a ideia da congruência é tão antiga quanto a ideia de número. "É um conceito primitivo, não se define e a sua noção é intuitiva" (1969, p.7). Para as autoras, desde cedo as crianças têm noção intuitiva de congruência, como por exemplo: a minha bola é igual à de Pedro; Cortei um quadradinho igual ao de 
Lúcia; Pelo golpe de vista as crianças fazem comparações. No entanto, isto não basta, pois coisas que à primeira vista parecem ser do mesmo tamanho, na realidade não o são.

Ainda dizem aceitar que congruência é a igualdade, mas entre figuras distintas. Duas figuras são congruentes quando, mediante deslocamento no plano, podem coincidir por superposição. Para elas, os deslocamentos podem ser: diretos (translações e rotações); indiretos (simetrias). Tratam das propriedades da congruência (reflexiva simétrica e transitiva) e propõem uma questão sobre Congruência, solicitando que se responda a atividade.

No dizer de Molina e Rico (1969), as crianças inicialmente usarão as expressões: do mesmo tamanho, do mesmo comprimento, da mesma forma, para exprimir a congruência. Posteriormente, ela usará o termo congruente, que deve ser introduzido, de maneira significativa, após o conceito. Da página 7 a 26, o livro traz inúmeros exercícios de aprendizagem e fixação. Na quinta unidade, o conteúdo apresentado são Ângulos, destacado na Figura 18.

Figura 18 - Problemas / Congruência - $4^{\mathrm{a}}$ Unidade

\section{5: unidade ANGULOS}
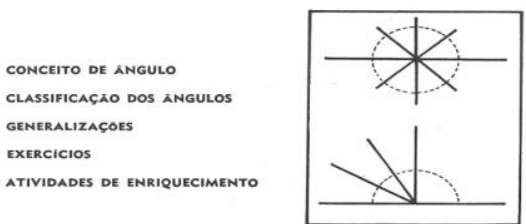

Fonte: Molina e Rico (1969).

\section{5 Ângulos - $5^{\mathrm{a}}$ Unidade}

Na unidade 5, as autoras destacam os objetivos propostos: formar o conceito de ângulo; conhecer a unidade de medida de um ângulo (grau); conhecer as denominações e valores dos ângulos; familiarizar as crianças com os instrumentos de medida de ângulo. Posteriormente, destacam os conteúdos a serem ensinados, como aponta a Figura 19.

Figura 19 - Conteúdos ensinados - $5^{\mathrm{a}}$ Unidade
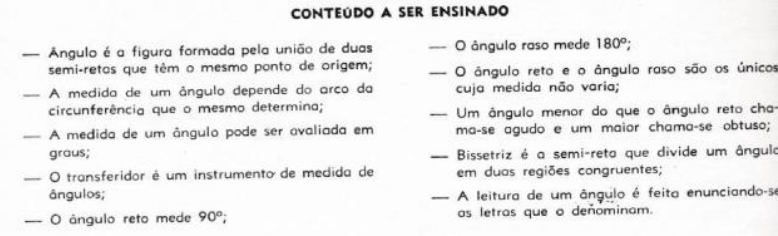

Fonte: Molina e Rico (1969).

Muitas atividades profissionais empregam ângulos para solucionar dificuldades, como por exemplo: o marceneiro, o pedreiro, o mecânico, entre outras profissões. Sistemas de elevada tecnologia empregam conceitos de ângulos para fazer os controles remotos, até radares em aeroportos. A lógica dos algarismos arábicos está na quantidade de ângulos que esses possuem. Alguma vez já se pensou qual o motivo de "1" significa "um", "2" significa "dois"? É pura lógica. Se alguém escrever o número em sua forma primitiva, vê-se que estão relacionados à Geometria, especificamente aos ângulos, conforme revela a Figura 20 número 1 tem um ângulo; o número 2 tem dois ângulos; o número 3 tem três ângulos e assim por diante. $\mathrm{E} \mathrm{o}$ «O» não tem ângulo nenhum.

Figura 20 - Algarismos Arábicos/Ângulos.

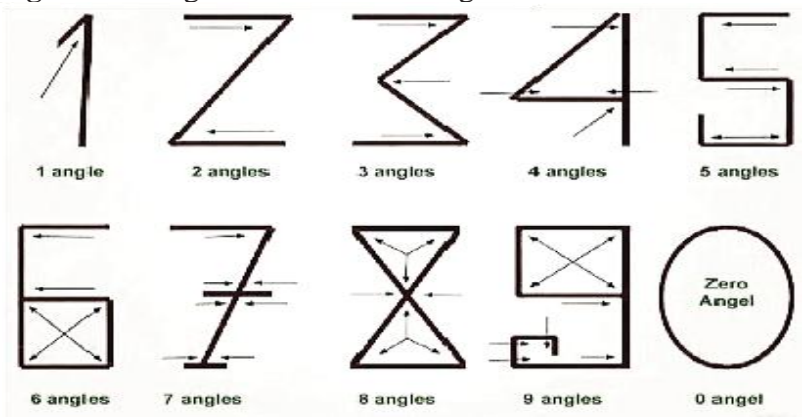

Fonte: http://professor-joselmo.blogspot.com.br

A $5^{\mathrm{a}}$ unidade informa sobre objetivos e concepções de ângulos e seguem os mesmos modelos de atividades com objetivos de fixação da matéria pelos alunos. As autoras ainda sugerem as atividades sobre ângulos.

Não se teve acesso aos $3^{\circ}$ e $4^{\circ}$ Volumes. O $5^{\circ}$ Volume possui três cadernos destinados às crianças. Os exercícios contidos no Caderno 1 se apresentam dosados e acompanham o desenvolvimento dos seguintes assuntos: ponto; linhas; figuras planas: quadrado, retângulo, círculo, triângulo; sólidos. Exercícios que vão da página 03 a 30. As autoras destacam um exemplo na Figura 21.

Figura 21 - Cilindro, Cubo e Esferas - $5^{\mathrm{a}}$ Unidade Caderno 1

Este boneco foi feito com um cilindro, um cubo e algumas esferas. Ligue os termos as partes corres pondentes no boneco.

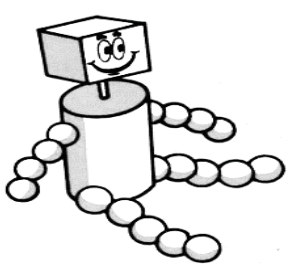

CILINDRO

CUBO

ESFERAS

Fonte: Molina e Rico (1969).

O caderno 2 apresenta conteúdos da página 33 a 97 a saber: linha reta, semirreta, segmento de reta; curvas abertas e fechadas; figuras planas: quadrado, retângulo, triângulo, losango, paralelogramo, círculo e trapézio; congruência; ângulo; posições da reta; triângulo; composição e decomposição de figuras; perímetro e sólidos.

Nos estudos acerca da composição e da decomposição de figuras para o cálculo de áreas, estudiosos como Bolda (2001) desenvolveram um estudo com o objetivo de investigar o papel do desenho em condição de aprendizagem. As autoras 
destacam o exemplo para que a criança complete o exercício proposto, conforme aponta a Figura 22.

Figura 22 - Exemplo de atividade - $5^{\text {a }}$ Unidade Caderno 1

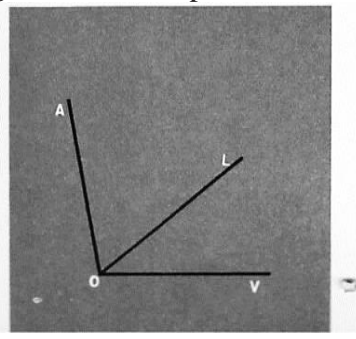

COMPLETE AS ORAÇÕES.

Esta figura representa um conjunto de semi-retas.

OA, OL, OV são............

A letra Ó

A........................

Fonte: Molina e Rico (1969).

Os exercícios contidos no caderno 3 destacam os conteúdos: semirreta e segmento de reta; posições relativas da reta; curvas abertas e fechadas; ângulos; figuras planas: triláteros e quadriláteros; congruência; perímetro; composição e decomposição de figuras; área e escala. Esses exercícios estão distribuídos da página 99 a 163. Destacam mais exemplos como a resolução de problemas que devem ser trabalhados em sala de aula, solicitando ao aluno que escreva sobre o que conhece a respeito da figura geométrica, apontados na Figura 23.

Figura 23 - Problema - 5a Unidade

\section{Resolva êste problema:}

A soma dos ângulos internos de um triângulo é sempre igual a 180 graus. $O$ triângulo retângulo tem um ângulo de 90 graus. Qual é a soma dos outros dois ângulos?

\section{Desenhe um triângulo retângulo}

Fonte: Molina e Rico (1969).

O $6^{\circ}$ Volume contempla os cadernos 4 e 5, destinados também para as crianças, os quais trazem vários exercícios abordando os seguintes conteúdos: posições relativas de retas e planos; curvas fechadas e abertas; polígonos; escala; área; composição e decomposição de figuras; círculo e circunferência: posições relativas de retas e circunferências; perímetro e área do círculo; movimento de rotação que gera o ângulo, a circunferência e o círculo e sólidos volume. Destacam mais exemplos para facilitar o trabalho do professor, direcionando os exercícios para a turma, destacado na Figura 24.

Figura 24 - Polígonos - 5ª Unidade

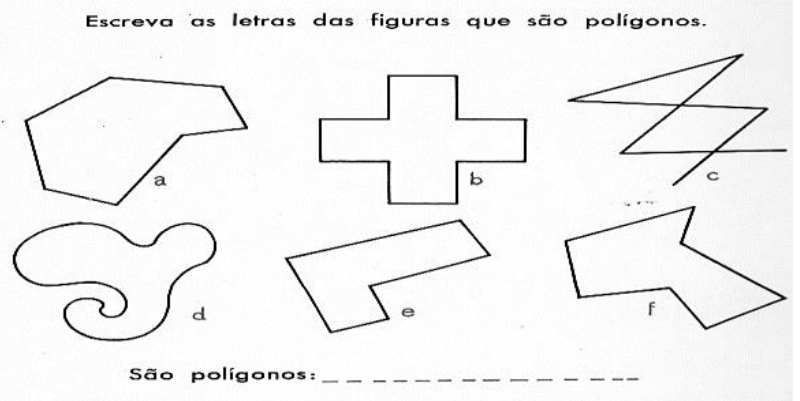

Fonte: Molina e Rico (1969).
As construções geométricas apresentadas em todos os cadernos seguem o mesmo padrão do problema acima apresentado. Não há explicação para os métodos. No Caderno 5 o conteúdo implica os sólidos: esferas, cubos e cilindros. Nesse estão presentes a planificação do cubo e a do paralelepípedo, com a instrução de recorte e monte os sólidos com as crianças, levando-as a observar que no cubo todas as faces são do mesmo tamanho e possuem a mesma medida, e que essas faces são os quadrados.

Estas observações podem ser analisadas quando se constata o Índice contemplando os conteúdos a serem ensinados: planificação; cubo; cilindro; prisma quadrangular; prisma triangular; prisma retangular; prisma pentagonal; pirâmide triangular; pirâmide quadrangular e cone.

Neste caderno, as autoras propõem que todos os exercícios de planificação sejam recortados e montados. Ao todo são 11 figuras geométricas para recortar e montar, oferecendo ao professor vários exemplos de como fazê-los, tais como o exemplo da Figura 25.

Figura 25 - Molde figura geométrica - Caderno 5

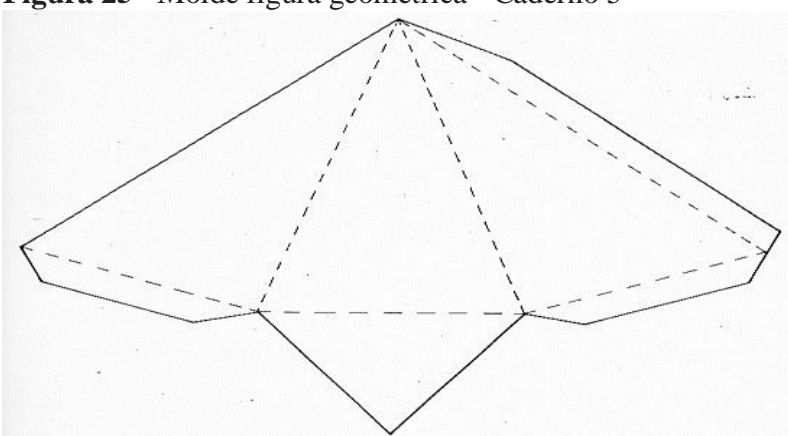

Fonte: Molina e Rico (1969).

Durante toda a análise se pode evidenciar o modo como as autoras constituíram a coletânea sobre o ensino da Geometria para o Ensino Primário e a Escola Normal. Sugerem dois aspectos em relação ao método: ora apresentam uma Geometria intuitiva, ora uma Geometria dedutiva.

\section{Conclusão}

Ao analisar os volumes destacados neste estudo se pode sinalizar que o ensino da Geometria presente na formação de professores e na escola primária do Estado de Mato Grosso, no período delimitado, constitui reelaborações de longa trajetória que foram construídas por essa matéria, que sempre foi pauta nas discussões nos primeiros anos escolares.

A Geometria presente na obra analisada se constitui como um saber elaborado ao longo do tempo pelas práticas escolares de tempos históricos diferentes. Segundo as autoras, a Pedagogia tradicional considerava como conteúdo os primeiros elementos sistematizados da Geometria indicados na obra como ponto, reta, plano, posições relativas de duas retas, polígonos entre outros, que foram construídos historicamente na cultura escolar.

No entanto, é importante salientar que, mesmo sendo 
um conteúdo deixado à margem do processo educativo, a Geometria deve ser trabalhada sempre relacionada ao cotidiano dos alunos. Faz-se necessário criar meios para que ocorra a compreensão dos conceitos geométricos, de trabalhos manuais, atividades práticas e lúdicas, cabendo ao professor potencializar o ensino desse conteúdo, desmistificando o conceito de que a Geometria é difícil de aprender.

No Estado de Mato Grosso não foi encontrada nenhuma pesquisa de cunho histórico que trata sobre o ensino de Geometria, em particular, das figuras Geométricas, as quais ocuparam lugar de destaque em toda a obra de Molina e Rico. Nesse sentido, este trabalho se constitui como uma fonte para futuras pesquisas, tendo em vista que a cada trabalho produzido surgem novas concepções, novos olhares e, portanto, novas formas de conceber a Geometria no currículo escolar.

Outro aspecto a considerar é a escassez de trabalhos com abordagem histórica relacionada ao ensino da Geometria, principalmente, no Estado de Mato Grosso. No Brasil, raras são as pesquisas que abordam a temática na perspectiva histórica. Atualmente, o grupo de Pesquisa Ghemat Brasil possui vários trabalhos desenvolvidos por pesquisadores, que contribuem sobremaneira para a compreensão do ensino da Geometria, desde os tempos mais remotos.

\section{Referências}

BOLDA, C.R.F. Olhar em perspectiva: análise da representação do espaço e suas implicações na visualização de figuras tridimensionais de geometria. Rev. Contrapontos Educ. Univali, v.1, n.3, p.119-127, 2001.

BLOCH, M. A apologia da História ou o ofício do historiador. Rio de Janeiro: Zahar, 2001.

CHARTIER, R. O mundo como representação. Estud. Avançados, v.11, n.5, p.173-191, 1991.

COMMANDINO, F. Euclides - Elementos de Geometria. São
Paulo: Edições Cultura, 1944.

DIENES, Z.P.; GOLDING, E.W. Exploração do espaço e prática da medição. São Paulo: EPU, 1977.

GADOTTI, M.F. Definições matemáticas do conceito de ângulo: influências da história, do movimento da matemática moderna e das produções didáticas nas concepções dos docentes. Piracicaba, SP, 2008.

KLINE, M. O fracasso da Matemática moderna. São Paulo: Ibrasa, 1976.

MIGUEL, A.; MIORIM, M. A. História na educação matemática: propostas e desafios. Belo Horizonte: Autêntica, 2004.

MOLINA, L.; RICO A.V. Criança, geometria, aritmética. São Paulo: Tabajara, 1969.

PAVANELLO, R.M. O abandono do ensino da Geometria: uma visão histórica. Rev. Zetetiké, v.1, n.1, 1993

PESTAlOZZI, J.H. Antologia de Pestalozzi. Buenos Aires: Losada, 1946.

PINHEIRO, N.V.L. O método intuitivo para o ensino de aritmética: a experiência da Escola Americana Paulista. In: ENCONTRO NACIONAL DE PESQUISA EM HISTÓRIA DA EDUCAÇÃO MATEMÁTICA, 2012.

ROQUE, T. História da Matemática: uma visão crítica, desfazendo mitos e lendas. Rio de Janeiro: Zahar, 2012.

SOUZA, R.F. Alicerces da pátria: história da escola primária no Estado de São Paulo (1890-1976). Campinas: Mercado de Letras, 2009.

VALENTE, W.R. Uma história da matemática escolar no Brasil, 1730-1930. São Paulo: Annablume/Fapesp,1999.

ZANATTA, B.A. O Legado de Pestalozzi, Herbart e Dewey para as práticas pedagógicas escolares. Rev. Teor. Prática Educ., v.15, n.1, p.105-112, 2012.

ZUIN, E.S.L. Construções geométricas, um saber escolar novamente para todos? In: SEMANA DA PÓS-GRADUAÇÃO DA UFMG, Belo Horizonte. 2002... Anais... Belo Horizonte: Universidade Federal de Minas Gerais, 2002. 